\title{
Isolation and Characterization of Rhizobium meliloti Isolated from Rhizosphere Soil and Roots of Fenugreek from Different Locations
}

\author{
Satyadev Prajapati ${ }^{*}$, M. S. Dadke ${ }^{2}$, S. Surekha ${ }^{2}$, S. Godika ${ }^{2}$ and V. Prasanna Krishna ${ }^{2}$ \\ ${ }^{1}$ Department of Plant Pathology, S.K.N. COA, SKNAU, Jobner, Jaipur \\ (Rajasthan)-303329, India \\ ${ }^{2}$ College of Agriculture, Latur, VNMKV, Parbhani, India \\ *Corresponding author
}

\section{A B S T R A C T}

\begin{tabular}{|l|}
\hline K e y w o r d s \\
$\begin{array}{l}\text { Rhizobium meliloti, root } \\
\text { nodules, rhizosphere soil, } \\
\text { fenugreek, cultural } \\
\text { characters, biochemical } \\
\text { test }\end{array}$ \\
\hline Article Info \\
\hline $\begin{array}{l}\text { Accepted: } \\
\text { 16 May } 2018 \\
\text { Available Online: } \\
\text { 10 June } 2018\end{array}$ \\
\hline
\end{tabular}

\section{Introduction}

The fenugreek (Trigonella foenum graecum Linn.) commonly called methi belongs to family Leguminoceae. There are two species of Trigonella genus which are of economic importance i.e. Trigonella foenum graecum (common methi) and Trigonella corniculata (Kasuri methi).Fenugreek is cultivated in India and other parts of world for leafy vegetables, condiments, medicinal as well as fodder purpose. Seeds of fenugreek are used as spice for preparation of different tasty dishes. (Rai and Yadav, 2005). According to Willems (2006), Beijerinck was the first to isolate the root nodule bacteria and named it as Bacillus radicicola. Later Frank changed the name to Rhizobium leguminosarum. Fenugreek has a potential to fix a substantial amount of atmospheric nitrogen. Inoculation of fenugreek with suitable strains of Rhizobium is expected to improve the quantity and quality of the produced seeds and consequently, the nutritional and economic status of the population will be improved. Rhizobium inoculation of fenugreek has been reported to increase the biomass of plant and seed production. Fenugreek was reported to fix $48 \%$ of its total $\mathrm{N}_{2}$ during the growing season (Singh et al., 2008). The Rhizobium isolates 
were rod shaped, Gram negative, acid and mucous producing. They were found to be temperature and $\mathrm{pH}$ sensitive, with optimum values of $29.4^{\circ} \mathrm{C}$ and 7.0 , respectively. The bacteria was sensitive to the antibiotics; chloramphenicol, kanamycin and streptomycin. It utilizes glucose, sucrose and starch as sole carbon source. The Rhizobium species isolated from fenugreek roots have the potential to produce industrially important enzymes; amylase and cellulose (Pawar et al., 2014).

\section{Materials and Methods}

\section{Collection of root nodules and soil samples}

The fresh and plump root nodules from the roots of fenugreek plants and rhizosphere soil samples from fenugreek were collected from the adjoining farmer's fields. These nodules and soil samples were brought to the laboratory and subjected for isolation from soil by serial dilution method and from root nodules by streak plate method on Congo-red Yeast Extract Mannitol Agar (CR-YEMA) medium.

\section{Isolation and purification of Rhizobium meliloti}

The soil samples and root nodules of fenugreek plant samples collected were subjected to isolations on selective medium. Isolation of rhizobia from root nodules of Trigonella foenum-graecum was done by the method suggested by Somasegaran and Hoben (1994). From each sample, two-three nodules were picked up and washed thoroughly with sterile distilled water. After washing, nodules were surface sterilized in $75 \%$ ethanol for $30-$ 40 second to remove wax coating if any and subsequently immersed in 3\% sodium hypochlorite for 3-4 min. Then nodules were immediately washed 5-6 times with sterile distilled water to remove traces of sodium hypochlorite. The surface-sterilized nodules were transferred to sterile tubes containing100 $\mu \mathrm{l}$ sterile distilled water. Nodules were crushed with the help of sterile glass rod and then one loopful of each nodule suspension was streaked on to sterilized plates of Congo red-yeast extract mannitol agar (CR-YEMA) medium. Then, the streaked plates were incubated at $28 \pm 2{ }^{\circ} \mathrm{C}$ in an inverted position for 2 to 4 days until colonies appeared along the lines of spreading. The soil samples were serially diluted in distilled water up to $10^{7}$ $10^{8} \mathrm{cfu} / \mathrm{ml}$ and isolated the Rhizobium on Congo red-yeast extract mannitol agar (CRYEMA) medium and incubated at $28 \pm 2{ }^{\circ} \mathrm{C}$. After completion of incubation period of 2 to 4 days, the plates were observed for development of the Rhizobium colonies.

Colonies of isolates were picked with sterile inoculating loop, streaked on sterile YEMA plates and incubated at $28 \pm 2^{\circ} \mathrm{C}$. The purity and uniformity of colony type was carefully examined through repeated re-streaking and a single well isolated colony was picked to YEMA medium in a petri plate and in conical flask containing YEMA broth for mass multiplication and incubated at $28 \pm 2^{\circ} \mathrm{C}$. (Somesagaran and Hoben, 1994 and Aneja, 2003).

\section{Characterization ofRhizobium meliloti isolates}

Visual characterization of colony morphology was done for isolation of pure cultures of Rhizobium. Nine such pure isolates were used for further studies and all tests were performed.

\section{Cultural characters}

The different isolates of Rhizobium collected from the fenugreek plants grown in pots and farmer's field in the nearby vicinity were grown on YEMA medium and incubated at 
28 $\pm 20 \mathrm{C}$ for 48 hours and observed for colony colour, shape and size (Aneja, 2003).

\section{Biochemical characters}

Biochemical characters of Rhizobium were studied by subjecting the bacterial isolates to various biochemical tests, viz. Gram's staining, catalase oxidation test, potassium hydroxide $(\mathrm{KOH})$ solubility test and starch hydrolysis test (Aneja,2003 and Vishunavat and Kolte, 2005).

\section{Gram's staining}

A loop full of the 24- 28 hrs. old bacterium suspension was smeared on clean glass slide, air dried and fixed by gentle heating on flame of the spirit lamp.

Aqueous Crystal violet solution (0.5\%) was spread over this smear for 30 to 60 second and then washed with running tap water for a minute; this stained smear was later flooded with Grams iodine solution for one minute and rinsed in tap water. Later decolorized with 95\% of ethanol until color runoff, washed with water and treated with Safranin as counter stain for about 10 seconds, washed with water, air/blot dried and observed under research microscope (make:- Olympus) at 40X.

\section{Catalase oxidation test}

A loop full of 24-28 hrs. old culture of test bacterium was placed on the clean glass slide, and to this a drop of $3 \%$ hydrogen peroxide $\left(\mathrm{H}_{2} \mathrm{O}_{2}\right)$ was mixed and allowed to react for few minutes and observed for the production of gas bubbles.

\section{KOH test (Potassium hydroxide)}

A drop of 3\% potassium hydroxide was placed on clean glass slide and to this $48 \mathrm{hrs}$. old test bacterial culture was mixed with clean inoculation loop and stirred for 10 second and observed for slime threads.

\section{Starch hydrolysis}

The autoclaved and cooled starch agar medium was poured in sterile glass Petri plates and on solidification of the medium, pure culture of the test bacterium was streaked and incubated for 96 hrs. at $28 \pm 2^{0} \mathrm{C}$.

Then these plates were flooded with lugol's iodine and allowed to react for few minutes.

\section{Results and Discussion}

\section{Collection of root nodules and soil sample}

Fenugreek root samples having nodules with pinkish coloured, present on tap root or lateral roots as a single or in clustered form and fenugreek rhizosphere soil samples were collected from the adjoining farmer's fields.

\section{Isolation and purification of Rhizobium meliloti}

The nine test isolates were isolated from rhizosphere soil and root nodules of fenugreek on basal culture medium YEMA with Congored, by applying serial dilution and streak plate method. Out of nine, five isolates were isolated from root nodules of fenugreek and nomenclatured as, LFRR-1, LFRR-2, LFRR-3, LFRR-4 and LFRR-5 and another four were isolated from fenugreek rhizosphere, nomenclature as LFRS-1, LFRS-2, LFRS-3 and LFRS-4 (Table 1). Colonies with whitish translucent appearance of Rhizobium were obtained on CR-YEMA medium after incubation at $28 \pm 2^{\circ} \mathrm{C}$ for two days. Generally the Isolates did not absorbed Congo red (Fig. 2), but isolates LFRS-1, LFRR-3, LFRS-3 and LFRR-5 slightly absorbed Congo red (Table 1, Fig. 1), showing the variation in absorption capacities of Congo red among the isolates. 
Fig.1 Showing Congo-red absorption

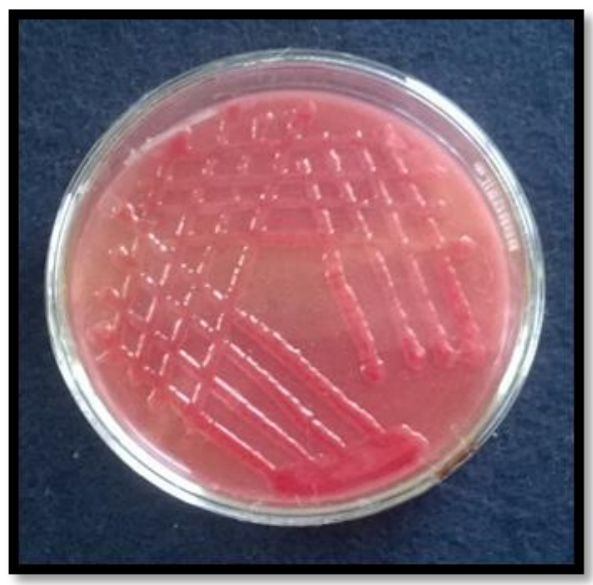

Fig.2 Showing no Congo-red absorption

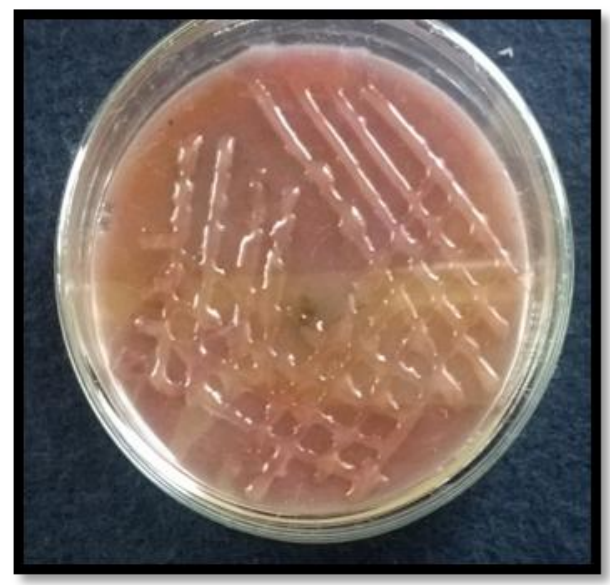

Fig.3 Whitish-translucent, rounded colonies of $R$. meliloti

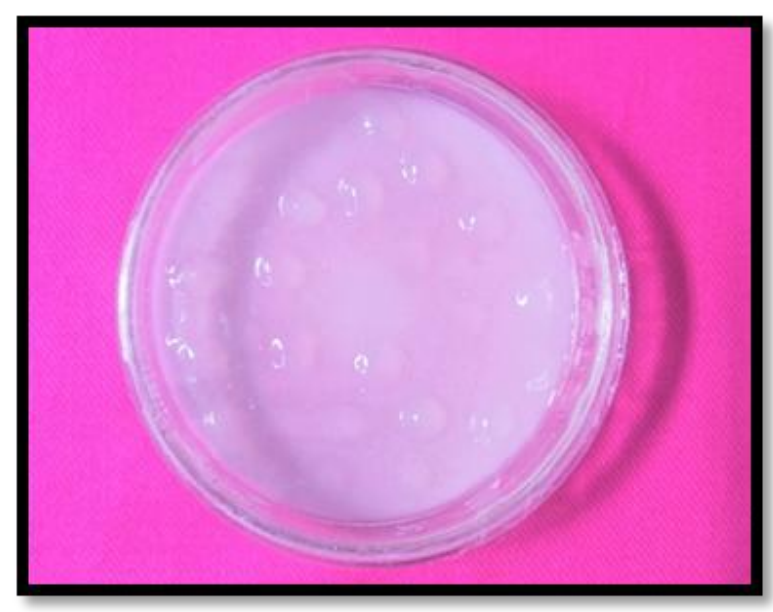

Fig.4 Gram Staining reaction

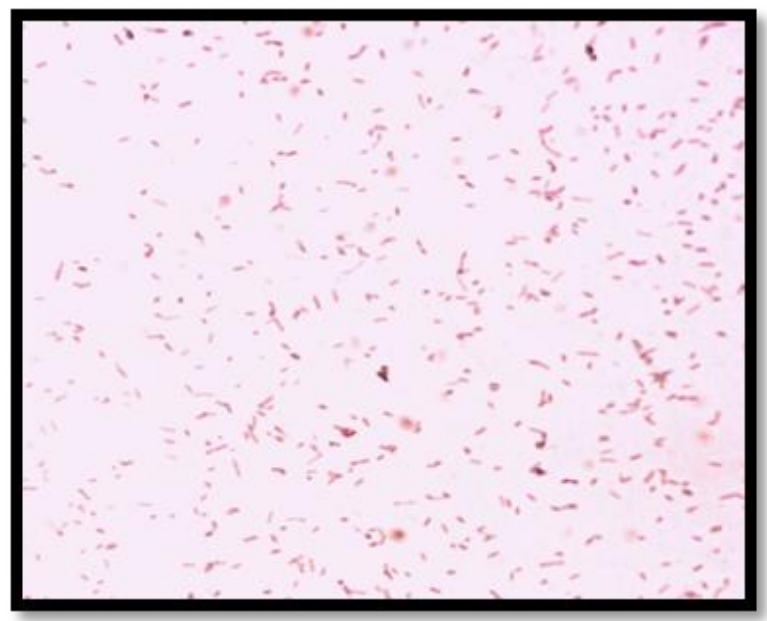


Table.1 Growth of Rhizobium meliloti isolates on CR-YEMA medium

\begin{tabular}{|c|c|c|}
\hline Sr. No. & Isolates & Growth on CR-YEMA medium \\
\hline $\mathbf{1}$ & LFRR-1 & Colorless \\
\hline $\mathbf{2}$ & LFRR-2 & Colorless \\
\hline 3 & LFRR-3 & light red \\
\hline $\mathbf{4}$ & LFRR-4 & Colorless \\
\hline $\mathbf{5}$ & LFRR-5 & light red \\
\hline 6 & LFRS-1 & light red \\
\hline 7 & LFRS-2 & Colorless \\
\hline 8 & LFRS-3 & light red \\
\hline 9 & LFRS-4 & Colorless \\
\hline
\end{tabular}

LFRR $=$ Latur fenugreek Rhizobium from root

LFRS $=$ Latur fenugreek Rhizobium from soil

CR-YEMA = Congo-red Yeast Extract Mannitol Agar

Table.2 Cultural characters of Rhizobiummeliloti isolates on YEMA

\begin{tabular}{|c|l|l|l|l|}
\hline Sr. No. & Isolates & Colony colour & $\begin{array}{c}\text { Colony } \\
\text { shape }\end{array}$ & Colony size $(\mathbf{m m})$ \\
\hline $\mathbf{1}$ & LFRR-1 & White & Round & 4.6 \\
\hline $\mathbf{2}$ & LFRR-2 & White & Round & 3.2 \\
\hline $\mathbf{3}$ & LFRR-3 & White & Round & 3.5 \\
\hline $\mathbf{4}$ & LFRR-4 & White & Round & 4.2 \\
\hline $\mathbf{5}$ & LFRR-5 & White & Round & 3.2 \\
\hline $\mathbf{6}$ & LFRS-1 & White & Round & 4.3 \\
\hline 7 & LFRS-2 & White & Round & 4.5 \\
\hline $\mathbf{8}$ & LFRS-3 & White & Round & 5.2 \\
\hline 9 & LFRS-4 & White & Round & 3.2 \\
\hline
\end{tabular}

LFRR $=$ Latur fenugreek Rhizobium from root

LFRS = Latur fenugreek Rhizobium from soil

YEMA = Yeast Extract Mannitol Agar

Table.3 Biochemical characters of Rhizobium meliloti isolates

\begin{tabular}{|c|c|c|c|c|c|}
\hline \multirow{2}{*}{ Sr. No. } & \multicolumn{4}{|c|}{ Isolates } & \multicolumn{4}{|c|}{ Characteristics } \\
\cline { 3 - 6 } & & $\begin{array}{l}\text { Gram } \\
\text { Reaction }\end{array}$ & $\begin{array}{l}\text { Catalase } \\
\text { Oxidation }\end{array}$ & $\begin{array}{l}\text { Potassium } \\
\text { hydroxide }\end{array}$ & $\begin{array}{l}\text { Starch } \\
\text { hydrolysis }\end{array}$ \\
\hline $\mathbf{1}$ & LFRR-1 & $-\mathrm{ve}$ & $+\mathrm{ve}$ & $+\mathrm{ve}$ & $+\mathrm{ve}$ \\
\hline $\mathbf{2}$ & LFRR-2 & $-\mathrm{ve}$ & $+\mathrm{ve}$ & $+\mathrm{ve}$ & $+\mathrm{ve}$ \\
\hline $\mathbf{3}$ & LFRR-3 & $-\mathrm{ve}$ & $+\mathrm{ve}$ & $+\mathrm{ve}$ & $+\mathrm{ve}$ \\
\hline $\mathbf{4}$ & LFRR-4 & $-\mathrm{ve}$ & $+\mathrm{ve}$ & $+\mathrm{ve}$ & $+\mathrm{ve}$ \\
\hline $\mathbf{5}$ & LFRR-5 & $-\mathrm{ve}$ & $+\mathrm{ve}$ & $+\mathrm{ve}$ & $+\mathrm{ve}$ \\
\hline $\mathbf{6}$ & LFRS-1 & $-\mathrm{ve}$ & $+\mathrm{ve}$ & $+\mathrm{ve}$ & $+\mathrm{ve}$ \\
\hline $\mathbf{7}$ & LFRS-2 & $-\mathrm{ve}$ & $+\mathrm{ve}$ & $+\mathrm{ve}$ & $+\mathrm{ve}$ \\
\hline $\mathbf{8}$ & LFRS-3 & $-\mathrm{ve}$ & $+\mathrm{ve}$ & $+\mathrm{ve}$ & $+\mathrm{ve}$ \\
\hline & LFRS-4 & $-\mathrm{ve}$ & $+\mathrm{ve}$ & $+\mathrm{ve}$ & $+\mathrm{ve}$ \\
\hline
\end{tabular}

-= Negative,$+=$ Positive

LFRR $=$ Latur fenugreek Rhizobium from root 
LFRS = Latur fenugreek Rhizobium from soil

The isolates were purified and mass multiplication on YEMA medium and YEMA broth for further study. Similar results were earlier reported by Kneen and Larue (1983), Yousef and Abdul Karim (2012) who reported that Rhizobium meliloti absorbed Congo red strongly and Tsegaye et al., (2015) reported that some isolates of Rhizobium isolated from fenugreek, slightly absorbed Congo red.

\section{Characterization of Rhizobium meliloti}

\section{Cultural characters}

Results (Table 2) indicated that the variation does not seen with the characters like, colony colour and shape except colony size which showed slight variation among the isolates of Rhizobium meliloti. The colonies of the isolates appeared to have a sticky nature, indicating the production of mucous substances. After two days of incubation, colonies were observed as whitish, rounded (Fig.3) and had a diameter in the range of 3.2 to $5.2 \mathrm{~mm}$. The isolate LFRS-3 recorded maximum colony diameter of $5.2 \mathrm{~mm}$, followed by the isolates viz., LFRR-1 (4.6mm), LFRS-2 (4.5mm), LFRS-1 (4.3mm) LFRR-4 (4.2mm) and LFRR-3 (3.5mm). Rest of the isolates, LFRR-2, LFRS-4 and LFRR-5 recorded the colony growth $3.2 \mathrm{~mm}$.

Result of present study revealed that all the isolates of Rhizobium meliloti showed whitish and rounded colonies with slight difference in colony size, Singh et al., 2008 reported that colonies of Rhizobium isolates, isolated from fenugreek were white, rounded, had a diameter from 5 to $7 \mathrm{~mm}$ and production of mucous substances which is indeed one of the characteristics Rhizobia, similar results were earlier reported by many workers like, Tamas et al., 2010, Jain et al., 2012, Prerna Rajpoot and Panwar 2013 and from different host like Berseem (Gauri et al., 2011), Faba bean
(Anteneh Argaw, 2012), Mungbean (Shraddha Bhatt et al., 2013 and Amin, 2014), Pea (Deshwal and Chaubey, 2014), Soybean (Pawar et al., 2014), Black gram (Satyanandam et al., 2014) Groundnut (Benson et al., 2015) and fenugreek (Tsegaye et al., 2015).

\section{Biochemical characters}

Different biochemical tests viz., Grams staining, Catalase oxidation test, $\mathrm{KOH}$ test (Potassium hydroxide), Starch hydrolysis, etc. were attempted in respect of $R$. meliloti and results (Table 3 ) revealed that all test isolates showed positive reaction with the catalase oxidation, potassium hydroxide and starch hydrolysis test and also gave negative reaction to Gram's staining (Fig. 4).

Similar results of biochemical tests viz., Gram staining, catalase test, potassium hydroxide $(\mathrm{KOH})$ test and starch hydrolysis test, in respect of $R$. meliloti observed under these investigations were earlier reported by several workers in different crops like, Singh et al., (2008), Gauri et al.,. (2011), Shahzad et al., (2012), Prerna Rajpoot and Panwar (2013), Singh et al., (2013).

\section{References}

Amin, N. (2014). Isolation and characterization of nodule bacteria from mungbean and investigation its to drought water stress on soybean plant. IJRRAS, 18(2): 188-192.

Aneja, K.R. (2003). Experiments in Microbiology Plant Pathology and Biotechnology. $4^{\text {th }}$ edition, New Age International publishers, New Delhi. Pp 607.

Anteneh Argaw (2012). Characterization of Symbiotic Effectiveness of Rhizobia Nodulating Faba bean (Vicia faba L.) 
Isolated from Central Ethiopia. Res. J. Microbi. 7: 280-296.

Beijerinck, M.W. (1888). Cultur des Bacillus radicola aus den knollchen. Bot. Ztg. 46: 740-750.

Benson, O., Beatrice, A., Regina, N., Koech, P.K., Robert, A.S. and Francesca, S. (2015). Morphological, genetic and symbiotic characterization of root nodule bacteria isolated from Bambara groundnuts (Vigna subterranean L. Verdc) from soils of Lake Victoria basin, western Kenya. J. App. Biolo. and Biotech. 3 (1): 1-10.

Deshwal, V.K. and Chaubey, A. (2014). Isolation and characterization of Rhizobium leguminosarum from root nodule of Pisum sativum L. J. Academia Industrial Res. (JAIR). 2: 464-467.

Frank, B. (1889). Ueber die pilzsymbiose der Leguminosen. Ber. Deut. Bot. Ges. 7: 332-346.

Gauri, Singh, A.K., Bhatt, R.P., Pant, S., Bedi, M.K. and Naglot, A. (2011). Characterization of Rhizobium isolated from root nodules of Trifolium alexandrinum. J. Agric. Techn. 7(6): 1705-1723.

Jain, R.K., Shrivastava, A. and Sharma, D.K. (2012). Isolation of crop specific indigenous Rhizobium strains and studies their effects on seed germination.Indian J. L. Sci. 2(1): 4145.

Kneen, B. E. and Larue, T. A. (1983). Congo red absorption by Rhizobium leguminosarum. Appl. Environ. Microbiol. 45 (1): 340-342.

Pawar, V.A., Pawar, P.R., Bhosale, A.M. and Chavan, S.V. (2014). Effect of Rhizobium on seed germination and growth of plants.J. Academia Indust. Res. (JAIR). 3(2): 84-88.

Prerna Rajpoot and Panwar, K. S. (2013). Isolation \& Characterization of Rhizobia and their Effect on Vigna radiata Plant. Octa. J. Biosci. 1(1): 6976.

Rai, N. and Yadav, D.S. (2005). Advances in vegetable production, Research Book Centre, New Delhi: 878-886.

Satyanandam, T., Babu, K., Rosaiah, G. and Vijayalakshmi, M. (2014). Screening of Rhizobium strains isolated from the root nodules of Vigna mungo cultivated in rice fallows for their phosphate solubilizing ability and enzymatic activities. British Microbiology Research Journal, 4(9): 996-1006.

Shahzad, F., Shafee, M., Abbas, F., Babar, S., Tariq, M. M. and Ahmad, Z. (2012). Isolation and biochemical characterization of Rhizobium meliloti from root nodules of alfalfa (Medico sativa). J. Anim. Plant Sci. 22(2): 522524.

Shraddha Bhatt, Vyas, R.V., Shelat, H. N. and Mistry, S. J. (2013). Isolation and Identification of Root Nodule Bacteria of Mungbean (Vigna radiata L.) for Biofertilizer Production. International Journal of Research in Pure and Applied Microbiology 3(4): 127-133.

Singh, B., Kaur, R. and Singh, K. (2008). Characterization of Rhizobium strain isolated from the roots of Trigonella foenum-graecum (fenugreek). African J. Biotech. 7(20): 3671-3676.

Singh, R., Arora, N. K., Gautam, P. and Lal, S. (2013). Enhancement of plant growth of Trigonella foenum-graecum by coinoculation of Pseudomonas fluorescent and Rhizobium for sustainability of agriculture. Asian. J. Pl. Sci. Res. 3(3): 74-79.

Somasegaran, P. and Hoben, H.J. (1994). Handbook for Rhizobia. SpringerVerlag. New York. USA.

Tamas, E., Mara, G., Laslo, E., Gyorgy, E., Mathe, I., Abraman, B. and Lanyi, S. (2010). Microbial products as natural alternative to fertilizers: isolation and 
characterization of nitrogen fixing bacteria. U.P.B. Sci. Bull., Series B, 72(3): 137-144.

Tsegaye, M., Assefa, F. and Zeleke, J. (2015). Symbiotic and phenotypic characterization of Rhizobium isolates nodulating fenugreek (Trigonella foenum-graecum L.) from North and East Shewa, Ethiopia. Int. J. Agron. Agri. Res. 7(1): 93-104.

Vishunavat, K. and Kolte, S. J. (2005). Essentials of Phytopathological
Techniques. Kalyani publishers, New Delhi. Pp 65-69.

Willems, A. (2006). The taxonomy of rhizobia: an overview. Plant and Soil.287: 3-14.

Yousef, Abu Z. and Abdul-Karim, S. (2012). Ecological studies on nitrogen fixing bacteria from leguminous plants at the north of Jordan. Afr. J. Microbiol. Res. 6(15): 3656-3661.

\section{How to cite this article:}

Satyadev Prajapati, M. S. Dadke, S. Surekha, S. Godika and V. Prasanna Krishna. 2018. Isolation and Characterization of Rhizobium meliloti Isolated from Rhizosphere Soil and Roots of Fenugreek from Different Locations. Int.J.Curr.Microbiol.App.Sci. 7(06): 1460-1467. doi: https://doi.org/10.20546/ijcmas.2018.706.173 